\title{
Design of Intelligent Hydraulic Excavator Control System Based on PID Method
}

\author{
Jun Zhang ${ }^{1,2}$, Shengjie Jiao ${ }^{1, *}$, Xiaoming Liao ${ }^{2}$, Penglong Yin ${ }^{2}$, Yulin Wang ${ }^{2}$, \\ Kuimao $\mathrm{Si}^{1}$, Yi Zhang ${ }^{1}$, and Hairong $\mathrm{Gu}^{1}$ \\ ${ }^{1}$ Key Laboratory for Highway Construction Technology and Equipment of Ministry of \\ Education, Chang' an University, Xi'an, Shangxi Province, P.R. China 710064 \\ jsj@mail.chd.edu.cn \\ ${ }^{2}$ Changlin Company, Changzhou, Jiangshu Province, P.R. China 213002
}

\begin{abstract}
Most of the domestic designed hydraulic excavators adopt the constant power design method and set 85\% 90\% of engine power as the hydraulic system adoption power, it causes high energy loss due to mismatching of power between the engine and the pump. While the variation of the rotational speed of engine could sense the power shift of the load, it provides a new method to adjust the power matching between engine and pump through engine speed. Based on negative flux hydraulic system, an intelligent hydraulic excavator control system was designed based on rotational speed sensing method to improve energy efficiency. The control system was consisted of engine control module, pump power adjusted module, engine idle module and system fault diagnosis module. Special PLC with CAN bus was used to acquired the sensors and adjusts the pump absorption power according to load variation. Four energy saving control strategies with constant power method were employed to improve the fuel utilization. Three power modes ( $\mathrm{H}, \mathrm{S}$ and $\mathrm{L}$ mode) were designed to meet different working status; Auto idle function was employed to save energy through two work status detected pressure switches, 1300rpm was setting as the idle speed according to the engine consumption fuel curve. Transient overload function was designed for deep digging within short time without spending extra fuel. An increasing PID method was employed to realize power matching between engine and pump, the rotational speed's variation was taken as the PID algorithm's input; the current of proportional valve of variable displacement pump was the PID's output. The result indicated that the auto idle could decrease fuel consumption by $33.33 \%$ compared to work in maximum speed of $\mathrm{H}$ mode, the PID control method could take full use of maximum engine power at each power mode and keep the engine speed at stable range. Application of rotational speed sensing method provides a reliable method to improve the excavator's energy efficiency and realize power match between pump and engine.
\end{abstract}

Keywords: Hydraulic excavator, energy saving, PID, CAN, negative flux system.

\footnotetext{
* Corresponding author.
} 


\section{Introduction}

Hydraulic excavator, which is widely used in mechanized construction such as in industrial and civil construction, farmland transformation, transportation, is multifunction earthmoving machinery. It consists of four parts namely power system, hydraulic system, working mechanism and electronic system. The energy flow in the excavator was like this: Mechanical energy was produced by the engine, then the mechanical energy was transferred to pressure energy by the hydraulic system to drive oil cylinder or hydraulic motor, finally, the pressure energy was change to mechanical energy to drive working mechanism. Its working state was a periodic operation, the periodic operation order is excavating, slewing, unloading and back to excavate.

Hydraulic excavator is a high power machine; the energy crisis attracted the energy saving research on excavator. The working time of the excavator is too long; most of them are working at day and night. Its operation load is of great variation, its average load is almost 50 60\% of maximum load(Guo Xiang'En, 2004).It was investigated that the energy utilization of excavator is about $30 \%$, most of power was wasted in hydraulic system and mechanical transmission(Xie GuoJing ,2008), so energy saving is a hot topic in excavator research.

Aiming to reduce the energy loss in hydraulic system, most of famous excavator companies united with hydraulic component companies to develop better hydraulic component and electronic technology, they search energy saving method in power system, hydraulic system and so on; from another method, they search energy saving method from power chain and focus on matching of the power between engine and hydraulic pump, power match between hydraulic system and load to optimize the power distribution of excavator. These researches gain great success. The hydraulic system was improved by the two methods, fix displacement pump were replaced by variable displacement pump; full power and sub power were replaced by cross power method. But it still couldn't meet the requirement of high performance, high reliability and automatic operation of excavator.

Along with the development of the sensor technology, control technology and servo-hydraulic technology, the excavator providers concentrated on developing electronic control system to save energy and improve the fuel utilization. Caterpillar company was the first to introduce the electronic control technology in excavator, it developed the first electronic monitor system to detect the operational fault in 1987(Zhang Dong, 2005). Then more famous companies took part in the development of electronic control system for excavator for energy saving, these system proved obvious energy saving, such as PMS system of O\&K company, AEC system of CAT, EC and PVC system of Hitachi, ITCS system of KOBELCO, CAPO system of HYUNDAI, ACS system of VOLVO, OLSS system of KOMATSU and so on(Guo Yong et al., 2006; Cheng DuWang, 2007), of which the electronic control system of Hitachi and KOMATSU was more perfect.

From 1960s, China began to research on designing hydraulic excavator, and imported technology from German in1980s. Up to date, the market share of the domestic companies was only $10 \sim 15 \%$, most of the market share was dominated by the foreign company such as DOOSAN, KOMATSU, HYUNDAI and Hitachi. The main reason was that the foreign companies own the core component of excavator, such as engine, hydraulic system and electronic control system, which were sealed for China. China 
adopt two methods to improve the domestic excavator performance, one way is creating joint venture Company with foreign famous company, but this is still not solving the technology sealed problem. Another is to develop excavator through research with colleges and universities. Guo Xiaofang(Guo Xiaofang et al., 1999) conducted an experiment on engine and pump united control system; later, Gao Feng(Gao Feng et al., 2001) research on valve control technology and give the power match between pump and engine in theory; Ji Yunfeng(Ji Yunfeng et al., 2003) research on the excavator control based on rotational speed of engine, Wu Xiaojian(Wu Xiaojian, 2005) analyze the performance of the engine and the pump and applied PID method to control the excavator. Even hybrid power was investigated on excavator for energy saving(Wang Dongyun et al., 2009).

Based on research with colleges and universities, domestic company has gain the core technology on fault monitor system in excavator, while electronic control system has a certain gap between domestic and foreign company. So, there is still scientific and economic value for researching on electronic control system and energy saving for excavator. In this paper, based on rotational speed of engine, an intelligent electronic control system was designed with CAN-BUS controller, and PID method was constructed to gain matching of power between the engine and the pump.

\section{Power Matching between Engine and Pump}

Inconsideration of the mechanical transfer efficiency between engine and pump, their power should be equal:

$$
P_{p}(t)=P_{e}
$$

Where $P_{p}(t)$ represents the power of hydraulic pump $(\mathrm{kW}), P_{e}$ represents the engine power $(\mathrm{kW})$.

$$
\begin{aligned}
& \text { Engine power: } P_{e}=\frac{T \cdot n_{e}}{9549} \\
& \text { Pump power: } P_{p}(t)=P_{p} \frac{Q_{p}}{60}=P_{p} \cdot q_{p} \cdot \frac{n_{p}}{60000}
\end{aligned}
$$

Where $\mathrm{T}$ is torque of engine(N.m), $P_{p}$ represents for the pressure of pump outlet (bar), $Q_{p}$ is pump flow (L/min), $q_{p}$ is displacement of the pump at each cycle $(\mathrm{mL} / \mathrm{r})$; $n_{p}$ is rotational speed of pump ( $\left.\mathrm{r} / \mathrm{min}\right)$.

Because the pump and the engine is of rigid connection, when excavator is at working, their torque and rotational speed should be equal and the torque should be constant, and at this work state, the power of pump is matching to engine. So, it could be conclude from equation (1) (3) that the pump torque $M_{p}$ could be calculated like equation (4). In the hydraulic system, the torque of the pump ( $T$ ) was decided by load pressure and pump flow rate.

$$
T=M_{p}=P_{p} \cdot q_{p} \cdot 2 \pi
$$




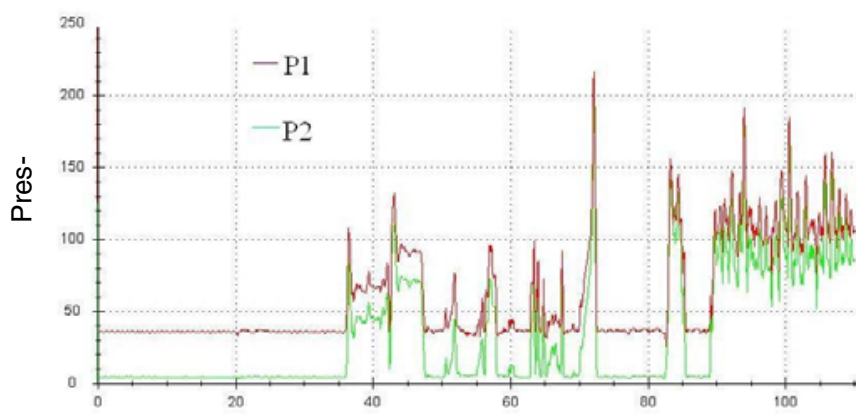

Fig. 1. Pump pressure changed with time during working

The electronic excavator was controlled by the constant power method. Fig.1 recorded the two pump pressure changed with time; it indicated that the pump pressure varied a lot during working. The pressure $\left(P_{p}\right)$ was decided by load, and pump outlet $\left(q_{p}\right.$ ) was controlled by an proportional valve, when the pressure changed, then $P_{p} \cdot q_{p}$ was varied with load, it would change the torque of the engine and caused the variation of rotational speed, the change of rotational speed would cause high fuel consumption. So, the drop of the rotational speed could reflect the variation of the load. The constant power controlled method expects the rotational speed be stable and the hydraulic system to be suitable with operator. In order to solve for adjusting the relation among the engine, the pump and the load, it need electronic controller to control the pump outlet based on the variation of rotational speed. The excavator electronic system was the key to constant power control method.

\section{Electronic Control System and Ennergy Saving Strategy}

\subsection{Intelligent Electronic Control System}

Fig. 2 shows the schematic diagram of the electronic control system, the energy saving system includes Cummins 6BTA5.9 engine, T5V displacement pump, negative flux hydraulic control system, linear throttle motor, throttle position sensor, two pump outlet pressure sensor, working state detecting sensor (Px and Py pressure sensor), engine speed setting knob and power mode knob, pump flow rate adjusting valve, three working solenoid valve (pressure up, travel high speed and pilot valve).

The electronic energy saving control system was constructed with CAN bus PLC and LCD monitor and was coded with CODESYS software. The control system was consisted of engine control module, pump power adjusted module, engine idle module and system fault diagnosis module. The PLC detects and processes the sensors' input signal, and then sends the signal to control the motor or value. The hydraulic system 


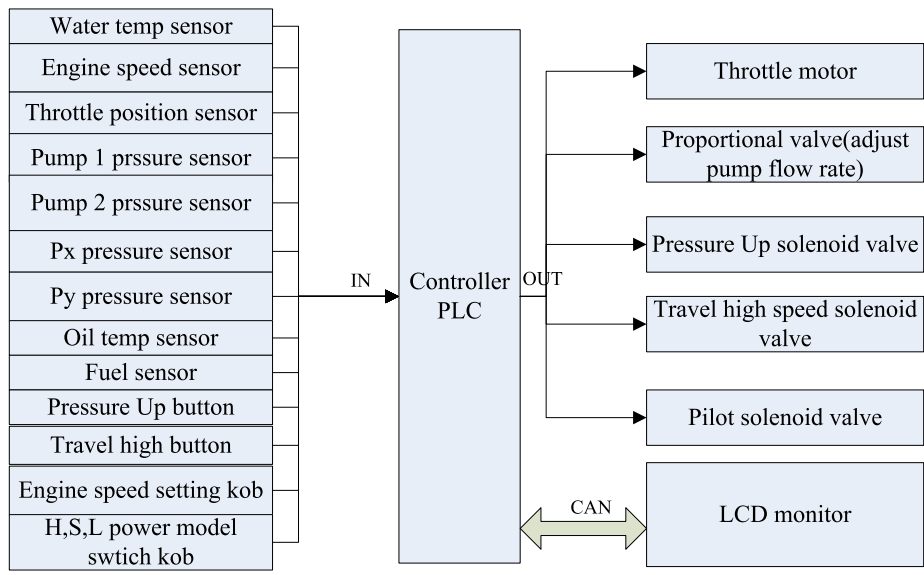

Fig. 2. Electronic control schematic diagram of excavator based on CAN bus controller

adopts two variable displacement pumps to transport power and drive load, electrohydraulic proportional technology was employed to control the flux of pump; these fluxes were controlled by adjusting the current through the electro-proportional valve by PLC. Fault diagnosis module was used to inspected engine and hydraulic fault through water temperature sensor of the engine, oil temperature sensor of the hydraulic system.

\subsection{Energy Saving Strategy}

The working state of excavator is very complex, not only heavy load excavating, but also light load leveling. Even at excavation, there has loosen and hard soil excavation. So excavator is always working at different status, it should set different output engine power to meet the complex working status, and adjust the throttle motor and displacement pump according to the requirement of operation. Thus, power mode control, auto idle control, transient overload control and PID power matching control method were used to design the energy saving electronic control system.

\subsubsection{Three Power Mode Control Method}

In order to meet different working status, the system designed three power modes$\mathrm{H}, \mathrm{S}$ and $\mathrm{L}$ power mode, their maximum power rang is $100 \%, 85 \%$ and $70 \%$ of the maximum power of engine separately. Fig. 3 is the engine's power and fuel consumption changed with engine speed. According to fig.3's data, the engine speed range of each power mode was defined in Table 1. H mode was designed for heavy load or rapid work status, $\mathrm{S}$ mode was designed for fuel economic utilization, and $\mathrm{L}$ mode was designed for finishing or leveling operation. At each power mode, operator could adjust the engine speed through engine setting knob, then the PLC drive the throttle motor to the setting speed. 


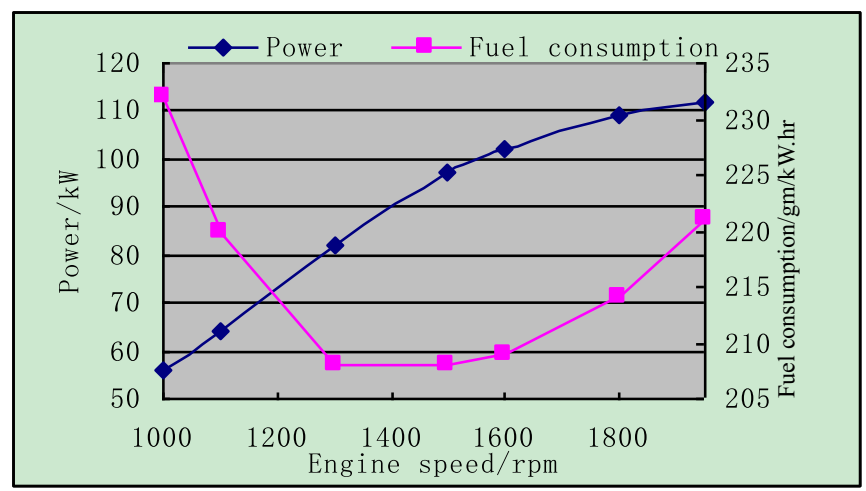

Fig. 3. Engine power and fuel consumption with engine speed

Table 1. Engine speed range of three power mode (unit: rpm)

\begin{tabular}{ccc}
\hline L mode & S mode & H mode \\
\hline $1000 \sim 1600$ & $1600 \sim 1800$ & $1800 \sim 1950$
\end{tabular}

\subsubsection{Auto Idle Control Method}

When the excavator is at waiting status, it should decrease the throttle opening position and let the engine run at idle status to save energy. The control system detects the idle status through two pressure sensors-Px and Py (see Fig.2). The pilot hydraulic system pressure is beyond 2Mpa during working, so when these two sensors' pressure is lower than $1 \mathrm{Mpa}$, it indicated that the excavator is at idle status. Fig. 4 is the control strategy for auto idle module. The auto idle speed is setting at $1300 \mathrm{rpm}$ according to Fig.3; at this speed, the fuel consumption is minimum $(208 \mathrm{gm} / \mathrm{kW} . \mathrm{hr})$. When engine is working at 1950rpm (H mode) and now excavator is at idle status, the PLC will pull down the engine speed to 1300rpm, it could decrease $33.33 \%$ of fuel consumption when considering the engine power is proportional to the engine speed.

$$
\text { Fuel consumpution drop }=\frac{n_{1}-n_{e}}{n_{1}}=\frac{1950-1300}{1950}=33.33 \%
$$

\subsubsection{Transient Overload Control Method}

The hydraulic system of the excavator remains pressure allowance, such as its normal high pressure is $33 \mathrm{Mpa}$, but when the pressure up solenoid is on, the system maximum pressure could be up to $35 \mathrm{Mpa}$, which couldn't cause damage to the hydraulic system within short time. The maximum pressure can't last long; otherwise it could short the serve life the hydraulic components. In order to improve the excavator's working efficiency, the electronic control system allow the load pressure is bigger than normal maximum pressure (33Mpa) for $8 \mathrm{~s}$, then the control system would decrease the engine speed to 1300rpm (idle status) and set the alarm speaker on to notice the operator, the control strategy was shown in Fig.5. It could be used in deep digging operation without consuming more fuel. 


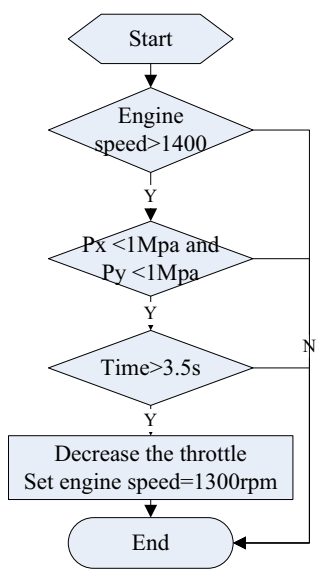

Fig. 4. Engine auto idle control module

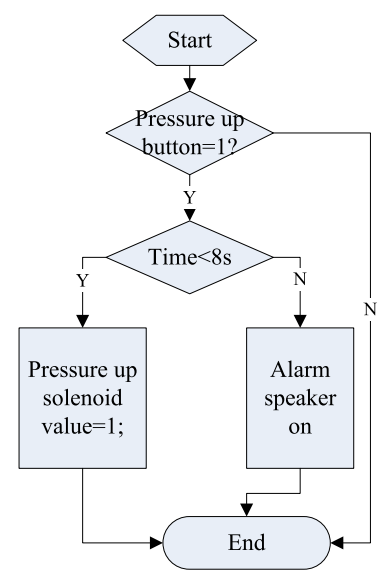

Fig. 5. Transient overload control module

\subsubsection{Power Matching between Pump and Engine with PID Control Method}

In the three power control mode, the power of the displacement pump was adjusted by electronic proportional valve, and the maximum power of pump was different at each power mode, only when the power of the pump is equal to the setting engine power, it is the constant power control strategy. When excavator is at working, the power of engine would decrease. In order to avoid engine speed drop, usually, the pump power was set at 85 90\% of engine power, so, it caused a lot of fuel wastage.

The rotational speed of engine variation could reflect the load variation; it could use rotational speed sensing technology to adjust the absorption power of pump through a proper current to the proportional valve. Consideration of the pump and the engine system belongs to large time-varying and nonlinear system; it couldn't get ideal control effect through engine speed drop. PID (proportion integral differential) method was a useful method to duel this nonlinear system; it was employed to adjust power matching between the pump and the engine during work. Fig.6 shows the PID control model for excavator control system. The PID control system was applied through increasing PID method in Codesys software. The PLC detects the throttle position timely and set the maximum engine speed $n_{0}$ at the chosen power mode. Then the PLC adjust the pump power through engine speed variation, if the detected speed $n_{e}(t)<n_{0}$, PLC decrease the proportional current to decrease the absorption

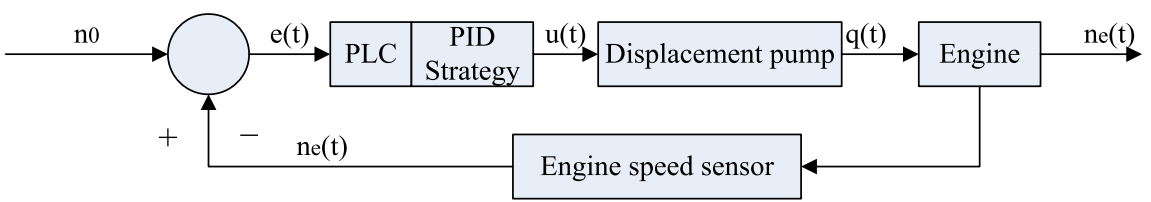

Fig. 6. Power matching adjustment though PID control method based on rotational speed sensing 
of pump power; when the engine power increase and $n_{e}(t)>n_{0}$, then PLC increase the pump power to let the absorption power equal to the maximum power of engine. So the PID control method could adjust the pump power around the maximum power of engine and improve the fuel utilization.

\section{Conclusion}

On the basis of analysis of the power matching principle among engine, pump and load, it was concluded that the engine speed could sense the variation of the load, which provides a reliable method to match power between the pump and the engine. On this basis, based on negative flux hydraulic control system, rotational speed control method was employed to design an intelligent hydraulic excavator control system to improve energy efficiency. An intelligent control system was constructed with special CAN bus PLC. The control system was consisted of engine control module, pump power adjusted module, engine idle module and system fault diagnosis module. Engine speed sensor and throttle position sensor were employed to acquire load information and control the engine power, Px and Py pressure sensor were employed to judge whether the excavator is at working or idle status. Two pressure sensor of pump outlet could provide load information for PLC controller. The proportional valve was employed to control the absorption power of pump. Three solenoid valves were employed to control the excavator movement. Water temperature sensor and oil temperature sensor was used to inspected engine and hydraulic fault.

Four energy saving control strategies were employed to control the excavator. Three power mode (H, S, L mode) control method were designed by operator's requirement. When united with PID control method, the engine's maximum power could be taken full use of and the engine speed could be kept stable, which would result in less fuel consumption. Auto idle control method could decrease fuel consumption automatically; it could decrease $33.33 \%$ of fuel compared when the excavator is at high speed without working. Transient overload control method could be used to be deep digging without consuming more fuel.

\section{References}

Xiangen, G.: Reserach on energy-saving fuzzy control system of hydraulic excavator [PH.D]. Jilin University, Chang chun (2004) (in Chinese)

GuoJing, X.: The research on electronic energy-saving control system of hydraulic excavator based on arm processor [Master]. GuangXi University, Nanling (2008) (in Chinese)

Dong, Z.: Study on energy-saving technology of hydraulic excavator based on power match [Ph.D]. Jilin University, Changchun (2005) (in Chinese)

Yong, G., Yong, C., Qinghua, H., et al.: View the development of electronic control system of excavator from INTERMAT 2006. Construction Machinery and Equipment 37(11), 40-43 (2006) (in Chinese)

DuWang, C.: Research on power match on multi function excavator [Master]. Central South University, ChangSha (2007) (in Chinese) 
Xiaofang, G., Weizhe, L., Zongyi, H.: Research on the combined control system of engine and oil pump in hydraulic excavator. Journal of TongJi University 27(3), 333-336 (1999) (in Chinese)

Feng, G., Yu, G., Pei-en, F.: Method of load matching control of hydraulic excavator's energy saving. Journal of TongJi University 29(9), 1036-1040 (2001) (in Chinese)

Yunfeng, J., Qiangen, C., Qinghua, H.: Analysis of control system of electromechanical internalization for hydraulic excavator of KOMATSU. Modern Machineary 2003(5), 4-6 (2003) (in Chinese)

Xiaojian, W.: Research on energy-saving control technology of hydraulic excavator [Master]. Central South University, Changsha (2005) (in Chinese)

Dongyun, W., Shuangxia, P., Xiao, L., et al.: Energy saving scheme of hydraulic excavators based on hybrid power technology. Computer Integrated Manufacturing systems 15(1), 188 196 (2009) (in Chinese) 